THE CANADIAN JOURNAL OF AUTISM EQUITY LA REVUE CANADIENNE DE L'ÉQUITÉ EN MATIÈRE D'AUTISME \begin{tabular}{l|l|l} 
VOLUME 1 & ISSUE 1 & APRIL 2021
\end{tabular}

\title{
What is it About our Story: Does Ergodicity help us Understand Equity from a Neurodiverse Perspective?
}

Joseph Sheppard, University of Victoria, Canada 


\title{
What is it About our Story: Does Ergodicity help us Understand Equity from a Neurodiverse Perspective?
}

\author{
Joseph Sheppard1
}

\begin{abstract}
This article explores the dynamics of equity and ergodicity in a psychological lab context including navigating consent (commitments) and transparency (debriefs). The article explores how evolutionary determinants are translated into competitive gameplay in human social interactions and how cooperative gameplay based on cultural stories counteracts harms associated with competition. Other themes that are explored is a love of learning at the center of cooperative storytelling. An Indigenous form of perspective-taking called etuaptmumk or "two-eyed seeing," developed by First Nations Mi'kmaw Elder Albert Marshall, is used as an example of ergodic intervention as a balance to cognitive biases. How are concepts of dignity and respect, as support for equity in needs, and a recognition of community member competencies and contributions, work to nurture a neurodiverse writing community where individuals can openly navigate consent, transparency, consensus, and inclusion? What are both the theoretical and practical implications of using multimodal expression such as writing on a neurodiverse community?
\end{abstract}

Résumé

Cet article explore la dynamique de l'équité et de l'ergodicité dans un milieu de laboratoire en psychologie, y compris la navigation du consentement (engagements) et de la transparence (suivis/comptes rendus). L'article explore comment les déterminants de l'évolution se traduisent par un jeu compétitif dans les interactions sociales humaines et comment un jeu coopératif basé sur des histoires culturelles contrecarre les préjudices associés à la compétition. D'autres thèmes sont explorés, comme l'amour de l'apprentissage au centre de la narration coopérative. Une forme indigène de prise de perspective appelée etuaptmumk ou "vision à deux yeux", développée par Albert Marshall, un aîné

mi'kmaq des Premières nations, est utilisée comme exemple d'intervention ergodique pour équilibrer les biais cognitifs. Comment les concepts de dignité et de respect, en tant que soutien à l'équité des besoins et à la reconnaissance des compétences et des contributions des membres de la communauté, permettent-

ils d'alimenter une communauté d'écriture neurodiversifiée où les individus

peuvent naviguer ouvertement dans le consentement, la transparence, le consensus et l'inclusion? Quelles sont les implications à la fois théoriques et pratiques de l'utilisation d'une expression multimodale telle que l'écriture sur une communauté neurodiverse?

1 University of Victoria, Canada 


\author{
Keywords \\ Equity, Ergodicity, Learning, Ethics, Writing \\ Mots clés \\ Équité, Ergodicité, Apprentissage, Éthique, Écriture
}

My name is Joseph Sheppard. I am diagnosed with autism, and I share psychology concepts to communicate stories about social repair. This story shares my perspective about "equity" in the context of consent, transparency, inclusivity, and the reward of sharing narrative experiences.

Themes associated with "equity" are often encountered in a psychology lab context. Sometimes I work as a lab instructor in a psychology methods course at the University of Victoria. In a lab setting, we learn the foundational and functional competencies required for doing psychological experiments. Foundational competencies are capacities to regulate behavior according to mutual commitments towards ethics and social protocols; functional competencies are capacities to complete necessary tasks for conducting experiments. In the lab, foundational and functional competencies work together to safeguard each participant's dignity according to their diverse needs. Consent is acquired to preserve dignity at each step of a series of carefully planned inclusive activities. And we science detectives must be transparent about how we intend participants to be impacted by each procedure in our activities.

In the lab, we use American Psychology Association (APA) ethics as a basis for our foundational competency, including its five principles of benevolence, personal integrity in science, responsibility to others, justice as inclusivity, and safeguarding each's diverse needs for dignity. These APA principles are shown to be valid and reliable constructs that optimize psychological safety for everyone participating in an experiment. Thus, maintaining the dignity of all participants is a baseline from where each contributes to tasks and associated responsibilities utilizing their respective competencies.

We have many practices in the lab, including not gossiping about others and respecting privacy and confidentiality, and giving space for debriefing participants so they may process their experiences and can ask any relevant questions. We safeguard each other's stories and names along with their bodies, spaces, and identities. We do not use APA ethics as a replacement for our cultural stories and moralities. Instead, APA ethics are used to share scientific knowledge in a way that is inclusive of humanity's many diverse cultural narratives.

In other words, when we practice safeguarding baseline dignity, we learn together to behave and interact responsibly to maintain each other's core needs. Maintaining this baseline of dignity as a social ensemble is indicative of developing social equity. Equity pertains to maintaining each's needs across their lifetime, inclusive of needs specific to their diversity. Each person's needs are different, so equality of needs does not equate to equality of resources. Should scientists ask if a needs-based approach to equity broadly equates to adjusting human societies from non-ergodic to synthetically ergodic ensemble systems? I am curious because I do not know. Scientists ponder what we do not understand in dialogue with other scientists. Ergodicity may refer to circumstances whereby an individual system (or agent) changes over its entire temporal 
lifespan in equal measure to the change experienced by the ensemble population as measured in a single instance.

I am not an expert in ergodicity. Therefore, I am more curious to find questions than share answers. As a psychology lab instructor, I sometimes build hypotheses from my curiosity to predict the cognitive unknown and question unexplained psychological processes. Does our conversation and actions in support of equity, conditioned to needs and responsibilities, balance our conversation and actions in support of competitive gameplay, conditioned to winning external rewards?

Ergodicity also refers to each agent's tendency to visit all the microstates within its system. When we think of physical needs, we may consider a host of goods and services needed by each person to function and retain connection without undue suffering or risk to safety. Therefore, human life may be described as a trajectory of experiences that visit all the microstates in their environment, inclusive of needs, indicative of experiencing a recognizably human life. Each agent is diverse, with a unique trajectory, so this family resemblance between human lives may be indicative of how humans can recognize a common sense of humanity in others across cultural narratives as social ergodicity.

When I think of being in a state of "need," I first consider psychological distress. When my needs are met, I am typically removed from psychological distress. My rationale for studying psychology was to help learn and discover optimal means of reducing psychological distress with the use of valid and reliable mechanistic processes. Part of the equity conversation is about inclusive access to the goods and services required for human bodies to have their needs met. To have Voice often requires being above a threshold of the noise of psychological distress.

There are physical needs met by diverse individuals in different measures, the withholding of which, below a threshold, becomes punishment conditioning rather than negative reward conditioning. Negative reward conditioning is withholding reward rather than evoking harm. Does equity serve as a measure of human needs that are irremovable without loss of dignity? In other words, at what point of needs scarcity does withholding reward become a punishment? Psychological distress may also cause marginalization of Voice and vice versa. This marginalization of Voice may result in personal absences from roles in cultural stories connecting families and generations. Human beings have language faculties, so we have signature Voices. We are super unique--all of us. Could ergodicity also pertain to a lifetime of stories being equal to a moment of interwoven stories connecting the population?

We have physical needs for resources and services required to live in dignity and safeguard Voice, but once having Voice, do we also have needs for sharing stories as a context for Voice? Could a human with a language faculty, a Voice, visit all the microstates within a human life story, not necessarily as a linear trajectory, but as a constellation of scene elements connected by story meaning?

A participant's experience in a lab experiment should be indicative of participation in any 
given experiment that sets its initial conditions to be consistent with APA ethics. Ergodicity is highly vulnerable to initial conditions where individual histories can significantly diverge from expected probabilities of population behaviour. Non-ergodic influences include evolutionary determinants like natural selection and human influences from conditioned cognitive biases and Ethics are used in the lab to control these initial and operational conditions so that each participant expects a safe experience, much like any other participant. Ethics are like game rules that set initial and boundary conditions for probable benevolent outcomes. However, evolutionary game theory conceptualizes human interactions along dimensions of dominant high-risk versus compliant low-risk orientations in competitive contexts that produce labeled "winners" and "losers."

Ethical principles not only contend with evolutionary game theory dynamics, but they also contend with each other. For example, "consent" typically enables everyone to opt-out of active participation, and "inclusivity" typically enables everyone to opt-in to active participation. Consent may strengthen personal boundaries, and inclusivity may act to reduce another's exclusion based on preconceived prejudicial personal boundaries. When boundaries are broken, psychological distress may increase. Thus, careful consideration of negative interactions between prescribed ethics may be required. May a measure of ergodicity be used to decide which ethics principle better decreases non-ergodicity?

APA founder and psychologist John Dewey described humans as a product of their urges, conditioning, and love of learning. Renninger, Sansone, and Smith (2004) describe the love of learning as a predisposition to keep re-engaging in a well-developed interest that causes positive feelings. Moreover, the love of learning is considered something regulated by the teacher-student relationship until they learn to self-regulate a self-generated motivation to continue learning and growing as students and sharing as teachers. For John Dewey, nurturing a healthy teacher-student relationship that promotes the independence and curiosity necessary for a self-regulated love of learning was central to the role of education in society. This dyadic relationship dedicated to colearning is at the centre of the policies that govern a psychology lab. In a lab, a healthy cooperative teacher-student relationship replaces competitor dyadic relationships between dominant and compliant agents. Each person learns and can use Voice conditioned to selfadvocating and taking responsibility for regulating an equity of needs versus instinctually aggressing others and intentionally conditioning others for control.

Thus, a love of learning offers hope to increase ergodicity in human society so that each person may expect a currency of needs equity that balances with a currency of external rewards. In this conceptualization, "wants" can be viewed as a subset of "needs" and not as a replacement or competitor to "needs."

I claim that equity is a specifically human form of ergodicity that emerges when empathy counterbalances non-ergodic external reward optimizing cognitive bias algorithms. For example, confirmation biases may generate preconceived notions of others that may pass costs to other individuals to reduce the variability in outcomes for a marginalized in-group. Ableism, in the context of neurodiversity, is the preference for people conforming to the average behaviours of the population, that is, neurotypical expressions, over a preference for neurodiverse folks. 
Confirmation bias can also be unconscious such as in the case of latent biases involved in malevolent stereotyping. Human confirmation biases often generalize individuals according to learned categories and projected negative connotations falsely associated with their intersecting identities or in-groups.

When we use story-guided cooperative game theory, we diverge from evolutionary gameplay that is optimized for competition; and even human cognitive biases that are further optimized by evolution for competition. Human history describes how systemic use of punishment and stereotyping have marginalized preconceived categories of people. Non-ergodicity increases when an out-group is marginalized based on preconceived categories; so that they carry the bulk of ensemble risk, and little responsibility or ensemble risk is carried by a preconceived privileged in-group. Loss of ergodicity causes stalls in mixing, including social mixing and interconnection of stories. Does this reduction in mixing cause people to stop visiting the full range of human experiences indicative of a person's unique story?

I use Martin Buber's distinction between human-to-human relationships that are either "I and Thou" as accepted interpersonal Voices or "I and It" as accepted foundationally and functionally competent relationships. I add another category of "I and Marginalized" as broken relationships with those socially constructed as Voiceless or as functionally dismissed. These three caste-like interpersonal relationships may be viewed as a by-product of non-ergodic evolutionary human behavioural tendencies. Thus, non-ergodic societies may differentiate between persons as accepted persons with Voices, persons as useful machines, and persons as estranged outsiders.

Como et al.'s (2020) research show that an autistic person may encounter ableism through other people's preconceived notions or stereotypes, marginalization or silencing, and microaggressions or behavioural punishments. These characteristics of ableism translate roughly to forms of ostracism indicative of outsourcing social costs based on preconceived biases towards neurodiversity identities. The lens of ableism often dismisses the value of neurodiverse Voices as either only technically useful or not being of use, but rarely worthy of being considered a "thou" as a meaningful role in another's story.

An evolutionary theorist may expect to sample organisms found in nature and see two entities in relative symbiosis, predator and prey, and a third class, those pushed from their environment due to the consequences of natural selection. However, an equity model based on ergodicity is wholistic and does not produce dualistic "winners" and "losers" and, therefore, is synthetic to how evolution typically operates.

Humans process the world of facts as meaningful in differing ways according to their stories, and we are all diverse by multiple variables. Ethics, as initial conditions, likewise do not always cohere together. However, could ergodicity be a measure of how some bridges work better to connect stories or how ethics find balance with each other? May some stories or ethics be more ergodic than others? Is the love of human learning more ergodic than automatic learning associated with urges and conditioning? How does nurturing a sense of responsibility to care for needs and a capacity for self-advocacy to recognize needs differ from reinforcing behaviours optimized for competition? How are we conditioned to debate cultural narratives in a manner 
that adds to systemic biases and further competitions between debate winners and losers rather than a goal of holistically seeking bridges in narrative perspectives leading to meaningful and transparent consensuses? How do we, those with language faculties embedded in a story, become enthusiastically consenting co-authors in our chosen, but "thou" inclusive, ergodic stories of tomorrow interlinked with contextual, cultural stories? I seek questions because I am a scientist in search of verifiable hypotheses, and questions are what spark the love of learning and the recognition of our narrative ground. Could our love of learning and storytelling become responsible for an ergodic turn to preserve our odd species with language faculties, well into time and well out to the stars? Could the idea of equity as ergodicity be better understood as Etuaptmumk? Etuaptmumk is an Indigenous Way of Knowing focusing on cooperative perspectivetaking using diverse stories from Elder Albert Marshall of the Mi'kmaw Nation. I do not identify as an Indigenous Voice from Turtle Island, so I encourage readers to learn more about Etuaptmumk from Indigenous Voices and Knowledge-Keepers. Humans are never disembodied from stories, needs, or lands. I wrote this article from the University of Victoria on Vancouver Island, Canada. I

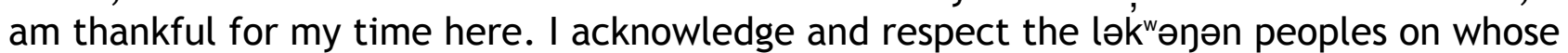
traditional territory the university stands and the Songhees, Esquimalt and WSÁNEĆ peoples whose historical relationships with the land continue to this day.

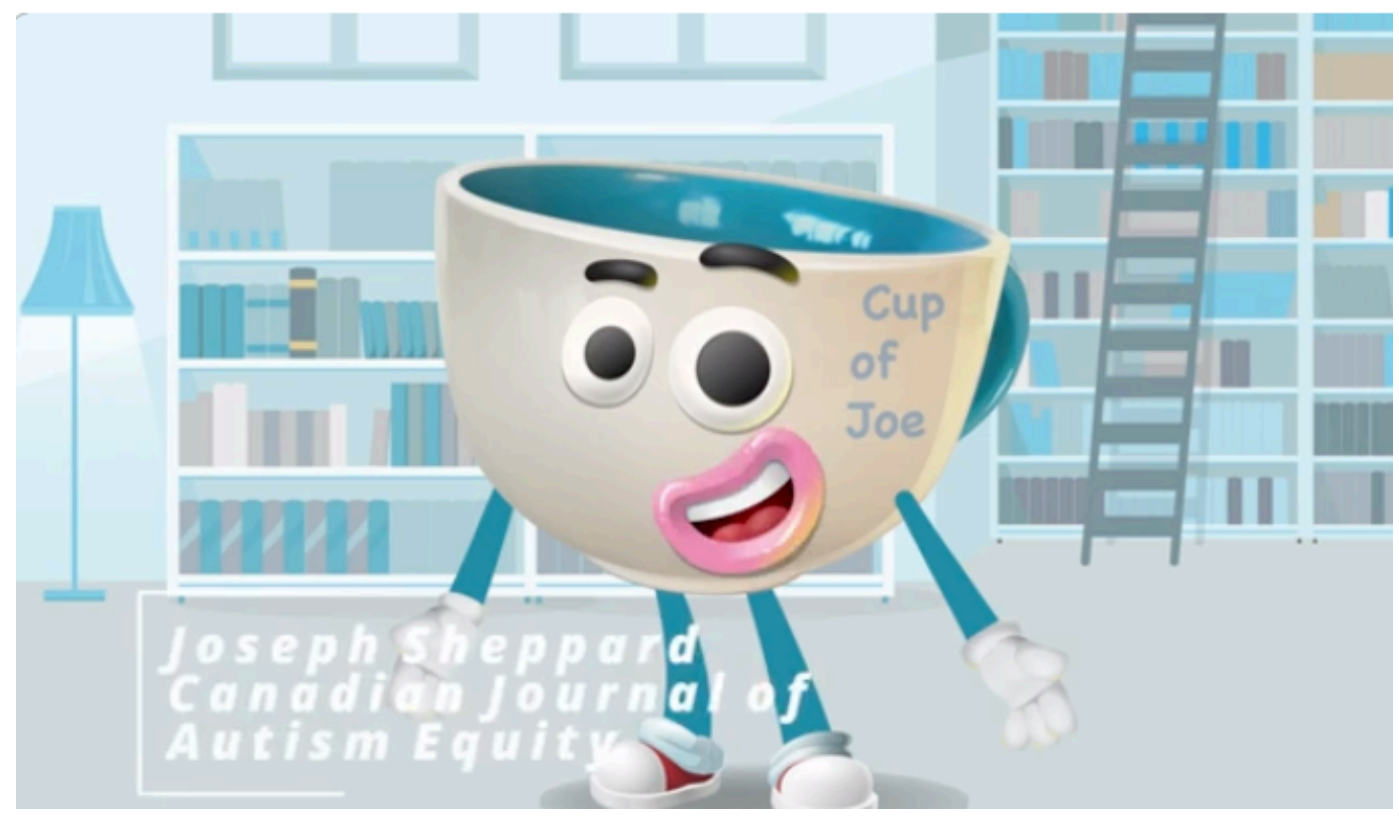

Watch the full video here. https://youtu.be/7CSjjsIX58w

\section{References}

Buber, M. (2012). I and Thou. eBooklt. com.

Chatwood, S., Paulette, F., Baker, R., Eriksen, A., Hansen, K. L., Eriksen, H., ... \& Brown, A. (2015). Approaching Etuaptmumk-introducing a consensus-based mixed method for health services research. International Journal of Circumpolar Health, 74(1), 27438.

Como, D. H., Floríndez, L. I., Tran, C. F., Cermak, S. A., \& Stein Duker, L. I. (2020). Examining unconscious bias embedded in provider language regarding children with autism. Nursing \& Health sciences, 22(2), 197-204.

Renninger, K., Sansone, C., \& Smith, J. L. (2004). Love of learning.

Young, G. (2017). Revising the APA ethics code. Cham, Switzerland: Springer International Publishing. 